\title{
Spontaneous Network Events Driven by Depolarizing GABA Action in Neonatal Hippocampal Slices are Not Attributable to Deficient Mitochondrial Energy Metabolism
}

\author{
Eva Ruusuvuori, ${ }^{1}$ Ilya Kirilkin, ${ }^{1}$ Nikhil Pandya, ${ }^{1}$ and Kai Kaila ${ }^{1,2}$ \\ ${ }^{1}$ Department of Biosciences, Finland, and ${ }^{2}$ Neuroscience Center, University of Helsinki, FI-00014 Helsinki, Finland
}

In two recent papers (Rheims et al., 2009; Holmgren et al., 2010), Zilberter and coworkers argue that the well known depolarizing GABA actions that take place at the cellular and network level in the neonatal hippocampus and neocortex in vitro are pathophysiological phenomena, attributable to deficient mitochondrial energy metabolism. In their experiments, supplementing the glucose-containing solution with weak-acid substrates of mitochondrial energy metabolism (such as $\beta$-hydroxy-butyrate, lactate, or pyruvate) abolished the spontaneous network events (giant depolarizing potentials; GDPs) and the underlying depolarizing actions of GABA. In this study, we made electrophysiological recordings of GDPs and monitored the mitochondrial membrane potential $(\Psi \mathrm{m})$ and intracellular $\mathrm{pH}\left(\mathrm{pH}_{\mathrm{i}}\right)$ in $\mathrm{CA} 3$ neurons in neonatal rat hippocampal slices. Supplementing the standard physiological solution with L-lactate did not produce a change in $\Psi \mathrm{m}$, whereas withdrawal of glucose, in the presence or absence of L-lactate, was followed by a pronounced depolarization of $\Psi \mathrm{m}$. Furthermore, D-lactate (a poor substrate of mitochondrial metabolism) caused a prompt inhibition in GDP frequency which was similar to the effect of L-lactate. The suppression of GDPs was strictly proportional to the fall in $\mathrm{pH}_{\mathrm{i}}$ caused by weak carboxylic acids (L-lactate, D-lactate, or propionate) or by an elevated $\mathrm{CO}_{2}$. The main conclusions of our work are that the inhibitory effect of L-lactate on GDPs is not mediated by mitochondrial energy metabolism, and that glucose at its standard $10 \mathrm{~mm}$ concentration is an adequate energy substrate for neonatal neurons in vitro. Notably, changes in $\mathrm{pH}_{\mathrm{i}}$ appear to have a very powerful modulatory effect on GDPs.

\section{Introduction}

Activation of $\mathrm{GABA}_{\mathrm{A}}$ receptors has been shown to lead to depolarizing and sometimes even functionally excitatory responses in a wide variety of immature neurons (for review, see Cherubini et al., 1991; Ben-Ari et al., 2007; Blaesse et al., 2009). This type of GABA action is generally thought to be a crucial mechanism in the generation of spontaneous network events in the developing brain (Ben-Ari et al., 1989; Sipilä et al., 2005). However, in two recent publications, Zilberter and coworkers (Rheims et al., 2009; Holmgren et al., 2010) have challenged the physiological relevance of the above observations, suggesting instead that depolarizing GABA actions and the consequent network events are pathophysiological manifestations of an energy deficiency in neonatal neurons kept under standard in vitro conditions. The main argument put forward in the above studies is that, although glucose is the primary metabolic substrate in the adult brain, immature neurons rely on the supply of additional substrates, such as ketone bodies, lactate, and pyruvate, to drive mitochon-

Received June 29, 2010; revised Sept. 1, 2010; accepted 0ct. 6, 2010.

This study was supported by grants from the Academy of Finland, the Sigrid Jusélius Foundation, and the Jane and Aatos Erkko Foundation. K.K. is a member of the Finnish Center of Excellence in Molecular and Integrative Neuroscience Research. We thank Prof. Karl E. Åkerman and Dr. Alexander Surin for their advice in the work on mitochondria, and Prof. Juha Voipio for his valuable comments on an early draft of this paper.

Correspondence should be addressed to Prof. Kai Kaila, Department of Biosciences, University of Helsinki, Fl00014 Helsinki, Finland. E-mail: Kai.Kaila@Helsinki.Fi.

DOI:10.1523/JNEUROSCI.3355-10.2010

Copyright $\odot 2010$ the authors $\quad 0270-6474 / 10 / 3015638-05 \$ 15.00 / 0$ drial ATP production. Hence, Zilberter and colleagues suggested that, when using preparations from neonatal rodents, the composition of the exogenous energy substrate pool is inadequate if only glucose is present.

All the conclusions by Zilberter's team regarding the state of energy metabolism in neonatal neurons are based on recordings of electrophysiological parameters such as the resting membrane potential, $\mathrm{E}_{\mathrm{GABA}}$, and giant depolarizing potentials (GDPs), which are promoted by depolarizing $\mathrm{GABA}_{\mathrm{A}}$ actions (Ben-Ari et al., 1989; Sipilä et al., 2005). The metabolic state of mitochondria, which Zilberter and colleagues proposed to be the locus of action of the additional (nonglucose) substrates, was not monitored in their studies. In the present study, we examined whether an enriched energy substrate pool suppresses network activity via changes in mitochondrial functions. Our main focus was on L-lactate, a well known substrate of oxidative energy metabolism both in neonatal and adult neurons (Erecinska et al., 2004; Raichle and Mintun, 2006). According to Holmgren et al. (2010), addition of $5 \mathrm{~mm}$ L-lactate into the standard physiological solution should provide in vitro conditions where energy metabolism is not compromised (see Discussion).

Our data, based on experiments with L- and D-lactate, propionate, and elevated $\mathrm{CO}_{2}$, show that inhibition of GDPs with application of L-lactate is not related to changes in the metabolic state of mitochondria. Instead, the fall in neuronal intracellular $\mathrm{pH}\left(\mathrm{pH}_{\mathrm{i}}\right)$ induced by the weak acids is sufficient to account for the suppression of GDPs. 


\section{Materials and Methods}

Experiments were approved by the Animal Ethics Committee of the University of Helsinki. Most experiments were performed on horizontal hippocampal slices $(400 \mu \mathrm{m})$ from postnatal day (P) 6-8 Wistar rat pups, as described previously (Sipilä et al., 2006a), with some additional observations at P4-P5. Data are reported as mean \pm SEM with the accompanying $n$ value referring to the number of slices from which data were obtained, unless otherwise stated. Statistical analyses were performed with Student's paired $t$ test. Least-squares cubic linear fit (York, 1966) and weighted correlation coefficient $(r)$ were calculated with lsqubic.m Matlab algorithm to determine the correlation between GDP frequency and intracellular acidification.

Electrophysiological recordings. The standard physiological solution contained the following (in mM): $124 \mathrm{NaCl}, 4 \mathrm{KCl}, 1.3 \mathrm{MgSO}_{4}, 2 \mathrm{CaCl}_{2}$, $1.1 \mathrm{NaH}_{2} \mathrm{PO}_{4}, 10$ D-glucose, and $25 \mathrm{NaHCO}_{3}$ (solutions equilibrated with $5 \% \mathrm{CO}_{2} / 95 \% \mathrm{O}_{2} ; \mathrm{pH} 7.4$ at the experimental temperature of $32^{\circ} \mathrm{C}$ ). The slightly higher GDP frequency attained with $4 \mathrm{~mm}$ versus $3.5 \mathrm{~mm}$ extracellular $\mathrm{K}^{+}$(Sipilä et al., 2005) was considered advantageous in experiments where a reduction of GDP frequency was expected to take place. Field-potential electrodes were filled with $150 \mathrm{~mm} \mathrm{NaCl}$ and recordings were done from submerged slices (double-sided perfusion at 4 $\mathrm{ml} / \mathrm{min}$, chamber volume $1 \mathrm{ml}$ ) from the CA3c-b area. Recordings were low-pass filtered at $2 \mathrm{kHz}$ and digitized at $5 \mathrm{kHz}$ using Strathclyde Electrophysiology WinEDR (provided by John Dempster) and band-passed at $0.2-25$ or $2-25 \mathrm{~Hz}$ for the illustrations. Only slices with a stable baseline frequency of GDPs $>0.05 \mathrm{~Hz}$ were used in the experiments. GDP frequency was quantified with an in-house program using a sliding bin of $120 \mathrm{~s}$ and a sliding window of $15 \mathrm{~s}$.

L- and D-Lactate (Sigma) and propionate (propionic acid sodium-salt; Fluka) were used at $5 \mathrm{~mm}$ concentration unless otherwise stated, and 3-(aminosulphonyl)-5-(butylamino)-4-phenoxybenzoic acid (bumetanide; Sigma) was applied at $10 \mu \mathrm{M}$. In glucose depletion experiments, $10 \mathrm{~mm}$ D-glucose was replaced with an equimolar amount of sucrose. In experiments where the $\mathrm{CO}_{2}$ content was increased from $5 \%$ to $8 \%$, $15 \mathrm{~mm} \mathrm{NaHCO}_{3}$ (final $\mathrm{HCO}_{3}^{-}$concentration $40 \mathrm{~mm}$ ) was added to maintain the extracellular $\mathrm{pH}$ constant, with an equimolar amount of $\mathrm{Na}$-D-gluconate (15 mM) in the control solution to keep the osmolarity constant.

Intracellular $p H$ measurements. The fluorescence imaging system consisted of an OptoLED light source (excitation wavelengths, $500 \pm$ 10 and $436 \pm 10 \mathrm{~nm}$; Cairn Research), an upright microscope $(60 \times$; water-immersion objective; numerical aperture, 0.9; Zeiss) and a PCO SensiCam CCD camera. Images were captured (at $0.1-0.2 \mathrm{~Hz}$ ) and analyzed with WinFluor software (provided by John Dempster). Slices were perfused at $2.5 \mathrm{ml} / \mathrm{min}$ (chamber volume, $1.5 \mathrm{ml}$ ). BCECF-AM (10 $\mu \mathrm{M}$; Invitrogen) was injected into the CA3c-b area via patch pipette and the fluorescent signal was measured and calibrated as before (Ruusuvuori et al, 2004). After loading, slices were left to recover for 20-30 min before recordings from the somatic region of CA3 pyramidal neurons were started.

Measurements of mitochondrial membrane potential. Hippocampal slices were bath loaded with $5 \mu \mathrm{M}$ rhodamine 123 (Rh123; Molecular Probes) for $25 \mathrm{~min}$ at room temperature. Before recordings were started, slices were washed for $\geq 30 \mathrm{~min}$. The fluorescence imaging system consisted of a Colibri light source (excitation wavelength, $510 \pm 8 \mathrm{~nm}$; emission, $>530 \mathrm{~nm}$; Zeiss), a Zeiss AxioExaminerZ1 upright microscope (60×, water-immersion objective; numerical aperture, 0.9$)$, and an AxioCam CCD camera. Images were captured at $0.1-0.03 \mathrm{~Hz}$ and analyzed with ImageJ software (National Institutes of Health). Slices were perfused at $2.5 \mathrm{ml} / \mathrm{min}$ (chamber volume, $1.0 \mathrm{ml}$; recording temperature, $32 \pm 0.5^{\circ} \mathrm{C}$ ). The regions of interest enclosed $4-8 \mathrm{CA} 3$ pyramidal cell somata. Mean fluorescence intensity is expressed as $f / f_{0}$, where $f_{0}$ is the baseline fluorescence intensity, and $\mathrm{f}$ the fluorescence intensity at a defined time point. The protonophore carbonyl cyanide4-(trifluoromethoxy) phenylhydrazone (FCCP, 4-10 $\mu \mathrm{m}$; Sigma) dissipated mitochondrial membrane potential $(\Psi \mathrm{m})$ (Duchen, 1992; Ortsäter et al., 2002), as indicated by an increase in Rh123 fluorescence.
A

Weak acid

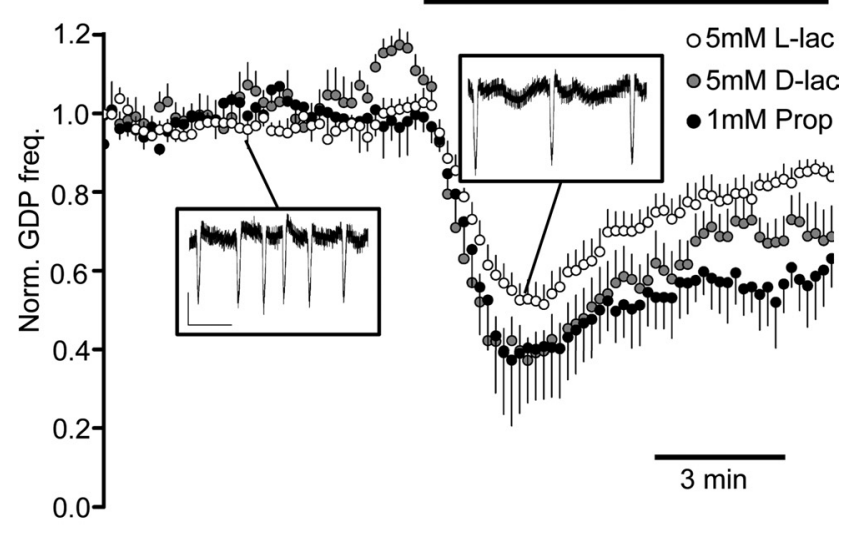

$B$

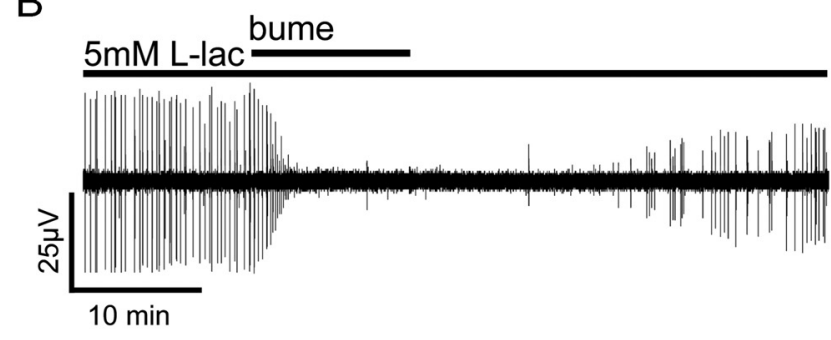

C

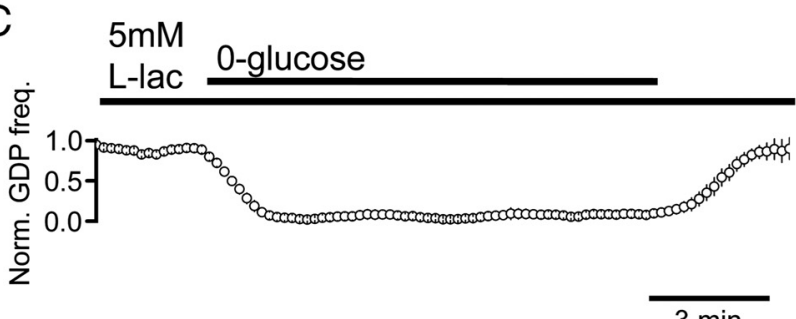

$3 \mathrm{~min}$

Figure 1. Inhibition of GDPs with weak acids is not related to changes in the metabolic state of mitochondria. $\boldsymbol{A}$, Weak acids $\mathrm{L}$ - and D-lactate (L-lac and D-lac, respectively; $5 \mathrm{~mm}$ ), as well as propionate (Prop, $1 \mathrm{~mm}$ ), inhibit GDP activity. Data show the normalized GDP frequencies (Norm. DGP freq.) ( \pm SEM) from 12,9, and 6 slices, respectively. In all individual field-potential recordings, the sliding average of GDPs was calculated over a bin of $120 \mathrm{~s}$, with a sliding interval of $15 \mathrm{~s}$. Insets show original traces bandpass filtered at $0.2-25 \mathrm{~Hz}$ from an experiment where 5 mm L-lactate was applied. Scale bars for insets, $5 \mathrm{~s} / 25 \mu \mathrm{V}$. B, Bumetanide (bume; $10 \mu \mathrm{M}$ ) reversibly abolished GDP activity in the continuous presence of $5 \mathrm{~mm}$ L-lactate (recording obtained $40 \mathrm{~min}$ after the beginning of lactate application; bandpass, $2.5-25 \mathrm{~Hz}$ ). C, Glucose depletion causes a progressive suppression of GDPs in the presence of $5 \mathrm{~mm} \mathrm{L-lactate.} \mathrm{Glucose}$ was replaced with an equimolar amount of sucrose. GDP frequency fully recovered when glucose concentration was restored to normal. Figure illustrates the sliding GDP frequency averaged from seven slices.

\section{Results}

GDPs are suppressed by both $\mathrm{L}$ - and D-lactate

Extracellular field potential recordings in the CA3 stratum pyramidale of P6-P8 hippocampal slices showed that bath application of $5 \mathrm{~mm}$ L-lactate produced a fast reduction in the frequency of GDPs to $51.4 \pm 4.9 \%(n=12 ; p<0.001)$ from the normalized baseline values. The maximum effect was reached within $\sim 2$ min (Fig. 1A). Notably, a similar rapid decrease in GDP frequency was caused by D-lactate (to $37.2 \pm 5.6 \% ; n=9 ; p<0.001$ ) (Fig. $1 A$ ). In the continuous presence of the weak acids, the decrease in GDP frequency was followed by a recovery toward its original level (after $20 \mathrm{~min}$ in L-lactate, GDP frequency was $87.6 \pm 4.0 \%$ of the control value and, in D-lactate, $86.1 \pm 5.6 \%$ of the control value). Removal of $\mathrm{L}-$ and $\mathrm{D}$-lactate after the recovery induced a rebound increase in GDP frequency (to $157.0 \pm 29.0 \%, n=4$ and 
$133.0 \pm 15.0 \%, n=9$, respectively). The transient suppression of GDPs cannot be related to an improvement in mitochondrial energy metabolism because the effects of the poorly metabolized isomer D-lactate were qualitatively and quantitatively similar to those obtained with L-lactate. Decreasing $\mathrm{K}^{+}$from 4.0 to $3.5 \mathrm{~mm}$ did not alter the effect of lactate (Holmgren et al., 2010, their supplemental Fig. 1). In experiments with $3.5 \mathrm{mM} \mathrm{K}^{+}, 5 \mathrm{mM}$ L-lactate application on P4-P5 slices reduced GDP frequency to $67 \pm 12 \%(p<0.05 ; n=5)$.

Propionate has been used as a standard tool to manipulate $\mathrm{pH}_{\mathrm{i}}$ in neurons and various other cell types (Roos and Boron, 1981). In accordance with the experiments with $\mathrm{L}$ - and D-lactate, bath application of $5 \mathrm{~mm}$ propionate caused a peak decrease in the frequency of the GDPs (to $19.5 \pm 6.0 \% ; n=4 ; p<0.001$ ) from the normalized baseline values. The more pronounced decrease in GDPs with $5 \mathrm{~mm}$ propionate can be explained on the basis of the differences in the $\mathrm{pK}_{\mathrm{a}}$ values of the weak acids used. With an identical total concentration of the two weak acids at a $\mathrm{pH}$ of $\sim 7.4$, the membrane-permeable protonated form of propionate $\left(\mathrm{pK}_{\mathrm{a}}, 4.87\right)$ is present at $\sim 10 \times$ higher concentration than that of lactate $\left(\mathrm{pK}_{\mathrm{a}}, 3.86\right)$, which leads to a much higher initial rate of net influx of $\mathrm{H}^{+}$(Roos and Boron, 1981; Mason et al., 1990). In agreement with this, a rapid and pronounced reduction of GDP frequency (to $37.2 \pm 8 \%, n=6$ ) (Fig. $1 A$ ) was seen in the presence of only $1 \mathrm{~mm}$ propionate.

In the immature CA3 pyramidal neurons, the driving force for $\mathrm{GABA}_{\mathrm{A}}$ receptor-mediated depolarizing currents is provided by the $\mathrm{Na}-\mathrm{K}-2 \mathrm{Cl}$ cotransporter isoform 1 (NKCC1)-mediated $\mathrm{Cl}^{-}$uptake (Yamada et al., 2004; Sipilä et al., 2006b). The fact the GDP generation was not blocked in the presence of L-lactate suggests that GABA remains depolarizing following a prolonged exposure to these weak acids. We examined this more closely in experiments with bumetanide $(10 \mu \mathrm{M})$, a specific blocker of NKCC1 that has been shown to inhibit GDPs in the neonatal rat hippocampus (Dzhala et al., 2005; Sipilä et al., 2006b). As expected, bumetanide completely blocked the occurrence of GDPs in the continuous presence of $5 \mathrm{~mm}$ L-lactate (lactate application for $>40 \mathrm{~min}, n=4$ ) (Fig. $1 \mathrm{~B}$ ).

\section{GDPs are suppressed upon glucose depletion}

Glucose depletion resulted in a near-complete block of GDPs. The maximum effect on frequency $(4.3 \pm 1.8 \%$ of baseline; $n=$ 9 ) was attained with a delay of 5-20 $\mathrm{min}$. When glucose depletion was done in the continuous presence of $5 \mathrm{~mm}$ L-lactate, there was a similar run-down of GDPs $(n=7)$ (Fig. $1 C)$. The latter result shows that, unlike glucose, $5 \mathrm{~mm}$ L-lactate alone is not able to support GDPs. During the onset of glucose depletion, GDP frequency decreased steadily with no signs of increased frequency or amplitude such as might be predicted if energy deficiency would cause pathophysiological hyperactivity (Holmgren et al., 2010).

\section{Mitochondrial membrane potential is not affected by L-lactate application in the presence of glucose}

It is well established that neuronal energy substrate utilization undergoes marked changes during development (Erecinska et al., 2004). However, findings of this kind do not justify the conclusion (Rheims et al., 2009; Holmgren et al., 2010) that glucose would be an inadequate energy substrate for neurons in in vitro experiments (Tyzio et al., 2010). This is an empirical question that needs to be tested. Hence, we looked at the consequences of glucose on GDPs in the absence and presence of L-lactate.

If, as argued by Zilberter and colleagues, neonatal neurons were energy depleted in standard physiological solution, addition
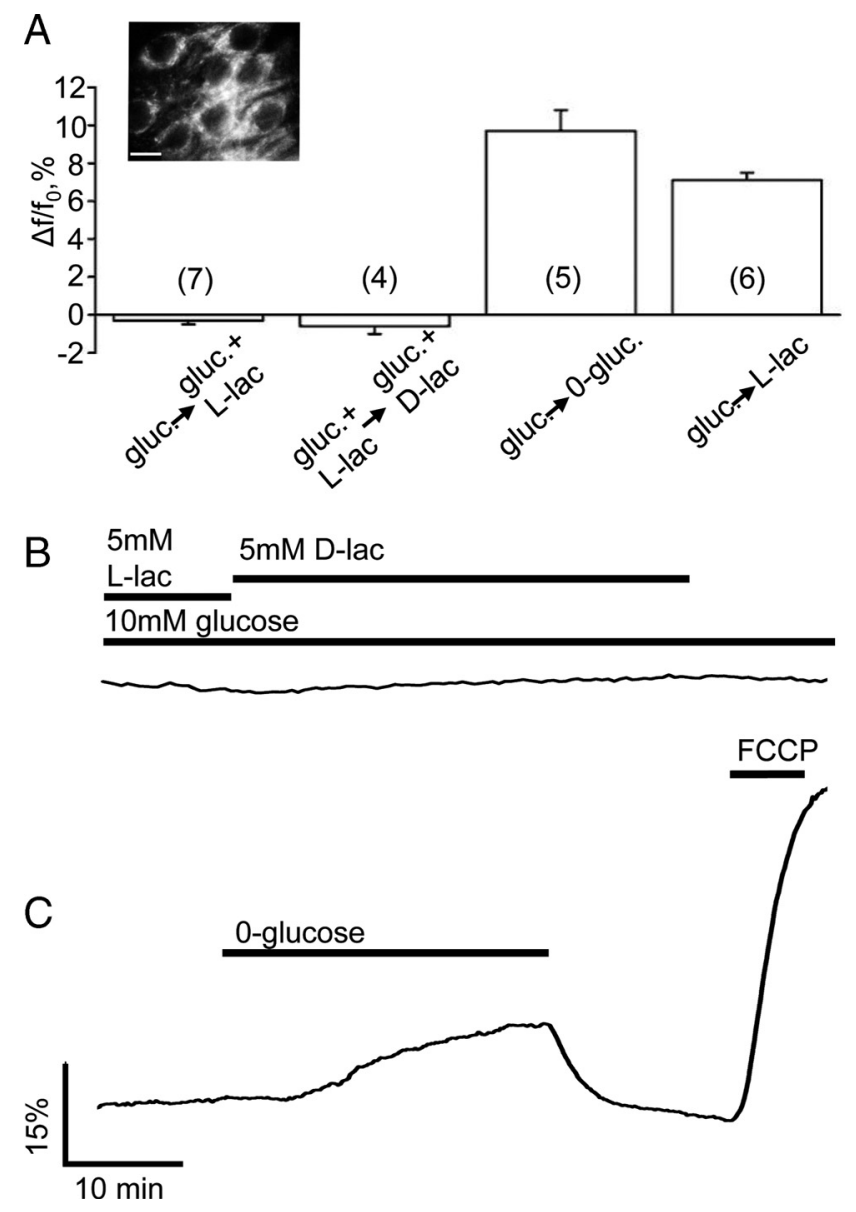

Figure 2. Depolarizing GABA actions are not attributable to deficient mitochondrial energy metabolism. $\boldsymbol{A}$, Mitochondrial membrane potential is not affected by $5 \mathrm{~mm}$ L-lactate (L-lac) or when L-lactate is replaced with D-lactate (D-lac). The bar diagrams represent the normalized Rh123 fluorescence of CA3 pyramidal neurons (+SEM, number of slices shown in brackets). Inset, CA3 pyramidal neurons in a slice preparation loaded with Rh123. Scale bar, $10 \mu \mathrm{m}$. B, A specimen recording showing the lack of effect when $5 \mathrm{~mm}$ L-lactate in standard solution is replaced with $5 \mathrm{~mm}$ D-lactate. C, Glucose (gluc) depletion causes a gradual and reversible depolarization of the mitochondrial membrane potential. When $\mathrm{FCCP}(4 \mu \mathrm{M})$ is applied to uncouple mitochondrial membrane potential, a profound increase in fluorescence intensity takes place, reflecting a depolarization of mitochondria.

of weak-acid substrate of oxidative energy metabolism would be expected to cause a change in the mitochondrial membrane potential, $\psi \mathrm{m}$. Therefore, we performed measurements of $\psi \mathrm{m}$ from CA3 pyramidal neurons with the fluorescent indicator Rh123. In seven of seven slices, addition of $5 \mathrm{~mm}$ L-lactate to the standard solution did not cause a detectable change in $\psi \mathrm{m}$ within CA3 neurons. The normalized Rh123 fluorescence after $5 \mathrm{~mm}$ L-lactate was $99.7 \pm 0.2 \%$ of the control value $(p=0.18)$ (Fig. $2 A)$. Furthermore, in the continuous presence of $10 \mathrm{~mm}$ glucose, substituting $5 \mathrm{~mm}$ L-lactate with the poorly metabolizable D-lactate had no effect on $\psi \mathrm{m}(99.4 \pm 0.4 \%, p=0.23, n=4)$ (Fig. $2 A, B)$. In striking contrast to the findings with L-lactate, glucose depletion produced a progressive, slowly developing increase in the Rh123 fluorescence, reflecting a gradual depolarization of $\psi \mathrm{m}$ (mean increase of the normalized fluorescence to $109.7 \pm .1 .1 \%, p=$ $0.001, n=5$ ) (Fig. 2A,C). The depolarization fully recovered when glucose concentration was restored. The obvious conclusion from the above data is that, in neurons of neonatal hippocampal slices, mitochondrial energy production can be fully supported by glucose. This conclusion gained further support in 

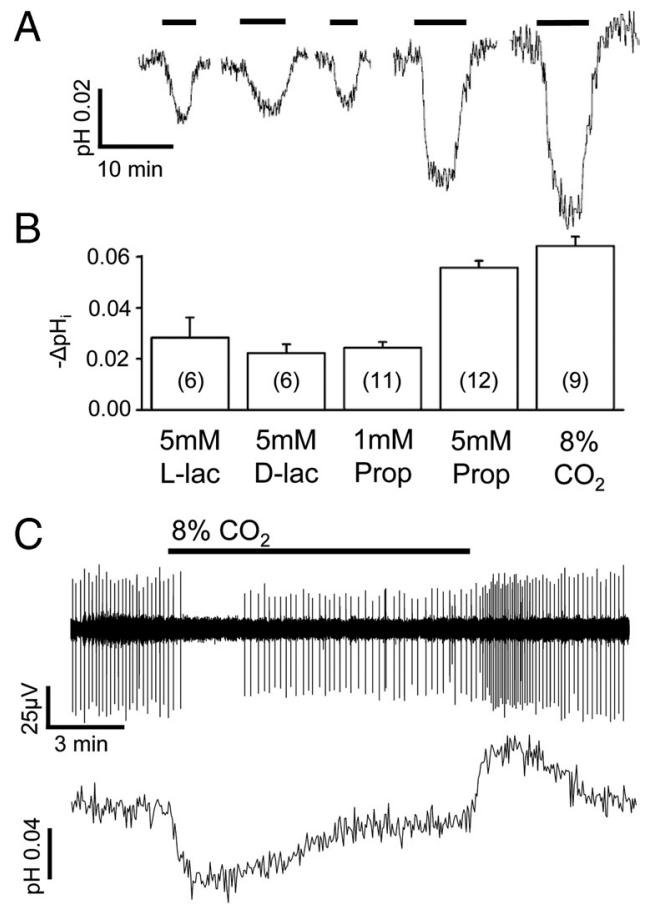

D

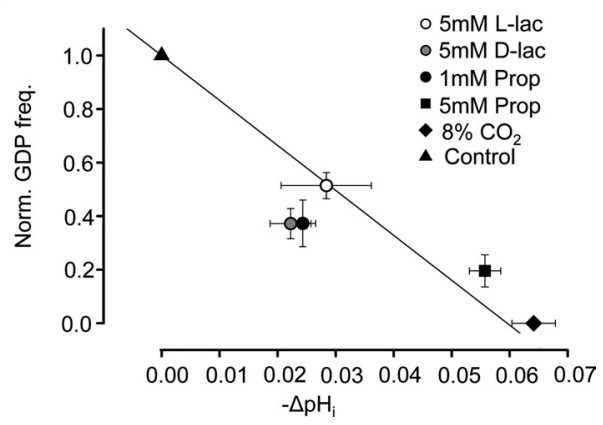

Figure 3. Weak acids and elevated $\mathrm{CO}_{2}$ content evoke an intracellular acidosis. $\boldsymbol{A}$, Bath application of $5 \mathrm{~mm}$ L- or D-lactate (L-lac and D-lac, respectively) induces an intracellular acidification comparable to that obtained with $1 \mathrm{~mm}$ propionate (Prop). A larger $\mathrm{pH}_{\mathrm{i}}$ transient is evoked with $5 \mathrm{~mm}$ propionate and by increasing $\mathrm{CO}_{2}$ from $5 \%$ to $8 \%$. Original $\mathrm{pH}$ traces showing averaged responses from two to five neurons. $B, C_{1}$ Combined data from $\mathrm{pH}_{\mathrm{i}}$ recordings of the above type (number of slices in brackets). $\mathrm{C}_{1} \mathrm{CO}_{2}(8 \%)$ transiently blocks $\mathrm{GDPs}$ and causes a prompt intracellular acidification. Top, Field-potential recording (bandpass, $2.5-25 \mathrm{~Hz}$ ). Bottom, $\mathrm{pH}_{\mathrm{i}}$ measurement from two neurons, baseline $\mathrm{pH}_{\mathrm{i}}$ 7.16. Downward deflection indicates intracellular acidification. $\boldsymbol{D}$, Inhibition of GDPs by L- and D-lactate and propionate or with elevated $\mathrm{CO}_{2}$ shows a strict correlation with the fall in $\mathrm{pH}_{\mathrm{i}}$. Reduction in the normalized GDP frequency (Norm. GDP freq.) is plotted versus the amplitude of the evoked intracellular acidification ( $r=-0.97)$.

experiments where glucose depletion caused an increase in Rh123 fluorescence even in the continuous presence of $5 \mathrm{~mm}$ L-lactate (to $107.1 \pm 0.4 \%, p<0.001, n=6$ ) (Fig. $2 A$ ).

We found no evidence suggesting that neonatal hippocampal neurons in vitro are under metabolic stress in the absence of L-lactate, or that adding L-lactate would have any beneficial effect on mitochondrial function.

\section{Modulation of intraneuronal $\mathrm{pH}$ with weak acids}

In the standard solution, the baseline $\mathrm{pH}_{\mathrm{i}}$ of the $\mathrm{P} 6-\mathrm{P} 8 \mathrm{CA} 3$ pyramidal neurons was $7.20 \pm 0.01(n=20$ cells from seven slices). Exposure to $5 \mathrm{~mm}$ L- or D-lactate resulted in a rapid acidification, which achieved its maximal value within $2 \mathrm{~min}$ (fall in $\mathrm{pH}_{\mathrm{i}}$ for D-lactate, $0.022 \pm 0.004, n=6$ cells from three slices; L-lactate, $0.028 \pm 0.008, n=6$ cells from three slices) (Fig. $3 A, B$ ).
Application of $1 \mathrm{~mm}$ propionate evoked an intracellular acidosis comparable to that obtained with $\mathrm{L}-$ and D-lactate $(0.024 \pm 0.002$, $n=11$ cells from four slices), whereas the $\mathrm{pH}_{\mathrm{i}}$ change upon exposure to $5 \mathrm{~mm}$ propionate was $0.056 \pm 0.003(n=12$ cells from four slices) (Fig. $3 A, B$ ).

We next asked whether the fall in neuronal $\mathrm{pH}_{\mathrm{i}}$ caused by the weak acids could account for their inhibitory action on GDP activity. Using changes in $\mathrm{CO}_{2}$ content is another standard way to manipulate cellular acid-base parameters (Roos and Boron, 1981; Kaila and Ransom, 1998; Dulla et al., 2005). Elevating $\mathrm{CO}_{2}$ from $5 \%$ to $8 \%$ at a constant extracellular $\mathrm{pH}$ caused a prompt intraneuronal acidosis $(0.064 \pm 0.004, n=9)$ (Fig. $3 A-C)$. In field potential recordings, $8 \% \mathrm{CO}_{2}$ caused a transient block of GDPs $(n=5)$ (Fig. 3C). Notably, in all experimental paradigms, the fall in $\mathrm{pH}_{\mathrm{i}}$ was paralleled by a decrease in GDP frequency, both of which gradually recovered toward their original levels. As shown in Figure 3D, the suppression of GDP frequency by the three weak carboxylic acids and elevated $\mathrm{CO}_{2}$ shows a striking quantitative dependence on the fall of $\mathrm{pH}_{\mathrm{i}}$, with a weighted correlation coefficient of -0.97 . Although these data do not imply that the soma (where the $\mathrm{pH}_{\mathrm{i}}$ responses are measured) is the subcellular compartment that mediates the effect of the acidosis on GDPs, it is evident that the suppression of GDPs shows a strict dependence on the intracellular acid load (see Discussion).

\section{Discussion}

In their recent studies, Zilberter and coworkers (Rheims et al., 2009; Holmgren et al., 2010) claimed that depolarizing GABA responses recorded in neonatal neurons in vitro are caused by an insufficient energy substrate pool. They showed that addition of substrates such as $\beta$-hydroxy-butyrate, pyruvate, or lactate to a glucose-containing solution blocked GDPs. According to the results presented in Holmgren et al. (2010), addition of exogenous lactate at $5 \mathrm{mM}$ concentration is sufficient to provide in vitro conditions where energy metabolism of the neonatal neurons is not compromised.

It is obvious from the available literature that D-lactate and propionate are not efficient substrates for mitochondrial energy production in the mammalian brain (Poole and Halestrap, 1993; Ros et al., 2001; Nguyen et al., 2007; Gibbs and Hertz, 2008). However, both D- and L-lactate as well as propionate caused a significant reduction in the frequency of GDPs, which was followed by a gradual recovery in the continuous presence of the weak acid. After the recovery from L-lactate-induced GDP suppression, bumetanide, an NKCC1-specific antagonist, fully blocked GDPs. These results indicate that, in contrast to the conclusions by Holmgren et al. (2010), the depolarizing GABA actions needed to drive GDPs are not abolished in the presence of L-lactate. Furthermore, direct measurements of the $\Psi \mathrm{m}$ showed that exogenous L-lactate is not needed for maintaining $\Psi \mathrm{m}$ in a standard glucose-containing physiological solution. In contrast to this, glucose depletion caused a gradual dissipation of the $\Psi \mathrm{m}$ and a near-complete block of GDPs, regardless of the absence or presence of L-lactate. Even in its initial phase, the energy-metabolic crisis that was evident after glucose depletion did not lead to neuronal hyperexcitability, as would be predicted on the basis of the hypothesis by Holmgren at al. (2010).

The effects of weak acids on GDPs can be readily explained on the basis of $\mathrm{pH}_{\mathrm{i}}$ changes. We found a quantitatively strict dependence (Fig. 3D) of the suppression of the GDP frequency on the intraneuronal acidosis brought about by the weak carboxylic acids and by elevating the $\mathrm{CO}_{2}$ level from $5 \%$ to $8 \%$. In addition to their effect on neuronal acid-base parameters (Chesler, 2003), 
carboxylic acids and elevated $\mathrm{CO}_{2}$ are not likely to share any other mechanism of action to influence neuronal functions. Depending on the local $\mathrm{pH}$-modulatory mechanisms, experimentally induced changes in $\mathrm{pH}_{\mathrm{i}}$ show variation among distinct subcellular compartments and microdomains (Willoughby and Schwiening, 2002), and the specific technique used for acidifying the neurons will influence the magnitude of the $\mathrm{pH}$ changes evoked in the soma and elsewhere. The present $\mathrm{pH}_{\mathrm{i}}$ measurements were done in the neuronal soma. This does not imply that the subcellular target of the pH-modulatory action on GDPs is the neuronal cell body, but our data demonstrate that the suppression of GDPs is strictly related to the net acid load imposed by the three carboxylic acids (Fig. 3). The full block achieved by elevated $\mathrm{CO}_{2}$ is in agreement with this quantitative relation. Identifying the molecular targets of the GDP-suppressing effect of the fall in $\mathrm{pH}_{\mathrm{i}}$ is beyond the scope of the present study. However, likely candidates include voltage-dependent $\mathrm{Na}^{+}$and $\mathrm{Ca}^{2+}$ channels and acidsensing $\mathrm{K}^{+}$channels (Tombaugh and Somjen, 1998; Dulla et al., 2005, 2009; Enyedi and Czirják, 2010).

In summary, our results show that the energy demands of the neonatal pyramidal neurons in hippocampal slices are fully met when glucose, used at the conventional in vitro concentration of $10 \mathrm{~mm}$, is the only exogenous energy substrate. Moreover, the acute suppression of GDP frequency upon weak-acid application has nothing to do with a change in oxidative energy metabolism as shown by direct measurements of $\Psi \mathrm{m}$. The present results imply that the lactate-induced decrease in GDP frequency observed by Holmgren et al. (2010) is attributable to an intraneuronal acidosis. The pronounced suppression of GDPs by a very small acid load (as seen with $1 \mathrm{~mm}$ propionate) indicates that neonatal neurons are exquisitely sensitive to changes in $\mathrm{pH}_{\mathrm{i}}$. This finding is likely to have important implications on the generation of endogenous network events under physiological and pathophysiological conditions (Helmy et al., 2010) in the developing brain.

\section{References}

Ben-Ari Y, Cherubini E, Corradetti R, Gaiarsa JL (1989) Giant synaptic potentials in immature rat CA3 hippocampal neurons. J Physiol 416: 303-325.

Ben-Ari Y, Gaiarsa JL, Tyzio R, Khazipov R (2007) GABA: a pioneer transmitter that excites immature neurons and generates primitive oscillations. Physiol Rev 87:1215-1284.

Blaesse P, Airaksinen MS, Rivera C, Kaila K (2009) Cation-chloride cotransporters and neuronal function. Neuron 61:820-838.

Cherubini E, Gaiarsa JL, Ben-Ari Y (1991) GABA: an excitatory transmitter in early postnatal life. Trends Neurosci 14:515-519.

Chesler M (2003) Regulation and modulation of $\mathrm{pH}$ in the brain. Physiol Rev 83:1183-1221.

Duchen MR (1992) Ca2+-dependent changes in the mitochondrila energetics in single dissociated mouse sensory neurons. Biochem J 283:41-50.

Dulla CG, Dobelis P, Pearson T, Frenguelli BG, Staley KJ, Masino SA (2005) Adenosine and ATP link P-CO2 to cortical excitability via $\mathrm{pH}$. Neuron 48:1011-1023.

Dulla CG, Frenguelli BG, Staley KJ, Masino SA (2009) Intracellular acidification causes adenosine release during states of hyperexcitability in the hippocampus. J Neurophysiol 102:1984-1993.

Dzhala VI, Talos DM, Sdrulla DA, Brumback AC, Mathews GC, Benke TA, Delpire E, Jensen FE, Staley KJ (2005) NKCC1 transporter facilitates seizures in the developing brain. Nat Med 11:1205-1213.
Enyedi P, Czirják G (2010) Molecular background of leak K+ currents: two-pore domain potassium channels. Physiol Rev 90:559-605.

Erecinska M, Cherian S, Silver IA (2004) Energy metabolism in mammalian brain during development. Prog Neurobiol 73:397-445.

Gibbs ME, Hertz L (2008) Inhibition of astrocytic energy metabolism by D-lactate exposure impairs memory. Neurochem Int 52:1012-1018.

Helmy M, Tolner EA, Vanhatalo S, Voipio J, Kaila K (2010) Brain alkalosis causes birth asphyxia seizures suggesting a novel therapeutic strategy. Ann Neurol, in press.

Holmgren CD, Mukhtarov M, Malkov AE, Popova IY, Bregestovski P, Zilberter Y (2010) Energy substrate availability as a determinant of neuronal resting potential, GABA signaling and spontaneous network activity in the neonatal cortex in vitro. J Neurochem 112:900-912.

Kaila K, Ransom BR (1998) pH and brain function. New York: Wiley.

Mason MJ, Mattsson K, Pasternack M, Voipio J, Kaila K (1990) Postsynaptic fall in intracellular $\mathrm{pH}$ and increase in surface $\mathrm{pH}$ caused by efflux of formate and acetate anions through GABA-gated channels in crayfish muscle fibres. Neuroscience 34:359-368.

Nguyen NH, Morland C, Gonzalez SV, Rise F, Storm-Mathisen J, Gundersen V, Hassel B (2007) Propionate increases neuronal histone acetylation, but is metabolized oxidatively by glia: relevance for propionic acidemia. J Neurochem 101:806-814.

Ortsäter H, Liss P, Akerman KE, Bergsten P (2002) Contribution of glycolytic and mitochondrial pathways in glucose-induced changes in islet respiration and insulin secretion. Pflugers Arch 444:506-512.

Poole RC, Halestrap AP (1993) Transport of lactate and other monocarboxylates across mammalian plasma membranes. Am J Physiol 264: C761-C782.

Raichle ME, Mintun MA (2006) Brain work and brain imaging. Annu Rev Neurosci 29:449-476.

Rheims S, Holmgren CD, Chazal G, Mulder J, Harkany T, Zilberter T, Zilberter Y (2009) GABA action in immature neocortical neurons directly depends on the availability of ketone bodies. J Neurochem 110:13301338.

Roos A, Boron WF (1981) Intracellular pH. Physiol Rev 61:296-434.

Ros J, Pecinska N, Alessandri B, Landolt H, Fillenz M (2001) Lactate reduces glutamate-induced neurotoxicity in rat cortex. J Neurosci Res 66:790-794.

Ruusuvuori E, Li H, Huttu K, Palva JM, Smirnov S, Rivera C, Kaila K, Voipio $\mathrm{J}$ (2004) Carbonic anhydrase isoform VII acts as a molecular switch in the development of synchronous gamma-frequency firing of hippocampal CA1 pyramidal cells. J Neurosci 24:2699-2707.

Sipilä ST, Huttu K, Soltesz I, Voipio J, Kaila K (2005) Depolarizing GABA acts on intrinsically bursting pyramidal neurons to drive giant depolarizing potentials in the immature hippocampus. J Neurosci 25:5280-5289.

Sipilä ST, Huttu K, Voipio J, Kaila K (2006a) Intrinsic bursting of immature CA3 pyramidal neurons and consequent giant depolarizing potentials are driven by a persistent $\mathrm{Na}+$ current and terminated by a slow $\mathrm{Ca} 2+-$ activated K+ current. Eur J Neurosci 23:2330-2338.

Sipilä ST, Schuchmann S, Voipio J, Yamada J, Kaila K (2006b) The cationchloride cotransporter NKCC1 promotes sharp waves in the neonatal rat hippocampus. J Physiol 573:765-773.

Tombaugh GC, Somjen GG (1998) pH modulation and voltage-gated ion channels. In: pH and brain function (Kaila K, Ransom BR, eds), pp 395 416. New York: Wiley.

Tyzio R, Allene C, Nardou R, Picardo MA, Yamamoto S, Sivakumaran S, Caiati MD, Rheims S, Minlebaev M, Ferré P, Khazipov R, Romette JL, Lorquin J, Cossart R, Khalilov I, Nehlig A, Cherubini E, Ben-Ari Y (2010) GABA action in immature cortical neurons neither depends on the availability of ketone bodies nor on pyruvate. J Neurosci, in press.

Willoughby D, Schwiening CJ (2002) Electrically evoked dendritic pH transients in rat cerebellar Purkinje cells. J Physiol 544:487-499.

Yamada J, Okabe A, Toyoda H, Kilb W, Luhmann HJ, Fukuda A (2004) Cl-uptake promoting depolarizing GABA actions in immature rat neocortical neurones is mediated by NKCC1. J Physiol 557:829-841.

York D (1966) Least-squares fitting of a straight line. Can J Phys 44:10791086. 